\title{
Fabrication and Density Functional Theory Calculations of Bromine Doped Carbon Nitride Nanosheets with Enhanced Photocatalytic Reduction of $\mathrm{CO}_{2}$ into Solar Fuels
}

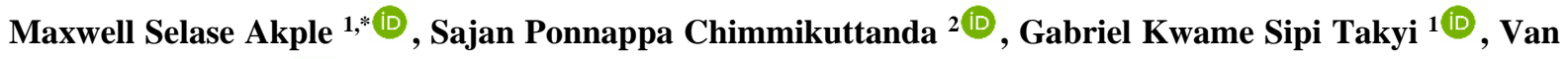 \\ Wellington Elloh 3,4 (D)
}

1 Mechanical Engineering Department, Ho Technical University, P.O. Box HP 217, Ho, Ghana.; makple@htu.edu.gh (M.S.A.); kwamesipi@gmail.com (G.K.S.T.);

2 R and D, Chemistry, VerdeEn Chemicals Pvt. Ltd, D-11, UPSIDC Industrial Area, Masoorie-Gulawati Road, Hapur District, Hapur, Uttar Pradesh 201015, India; sajan.saj@ rediff.com (S.P.C.);

3 Department of Materials Science and Engineering, CBAS, University of Ghana, Ghana; ellohvw@ gmail.com (V.W.E.);

4 Department of Physics, University of Petroleum and Energy Studies (UPES), Dehradun, India;

* Correspondence: makple@htu.edu.gh;

Received: 10.02.2021; Revised: 5.03.2021; Accepted: 8.03.2021; Published: 25.03.2021

\begin{abstract}
A promising technology to address the global environmental challenges and solar-to-fuel conversion development is photocatalysis. Thus, this study was conducted to fabricate ultrathin $\mathrm{Br}$ doped $\mathrm{g}_{-} \mathrm{C}_{3} \mathrm{~N}_{4}$ nanosheet for photocatalytic reduction of $\mathrm{CO}_{2}$ into solar fuels. The sample was produced by a mixture of dicyandiamide with ammonium bromide $\left(\mathrm{NH}_{4} \mathrm{Br}\right)$ in water, dried, calcinated, and exfoliated in methanol by ultrasonication. Compared to the pure $\mathrm{g}-\mathrm{C}_{3} \mathrm{~N}_{4} \mathrm{NS}$, the $\mathrm{g}-\mathrm{C}_{3} \mathrm{~N}_{4} \mathrm{NS}-\mathrm{Br}(0.5 \mathrm{~g})$ sample exhibited unique characteristics such as high porosity, large surface area, excellent visible lightharvesting ability, effective charge separation, and mobility of charge carriers with enhanced photocatalytic $\mathrm{CO}_{2}$ reduction into solar fuels (i.e., $\mathrm{CH}_{4}$ and $\mathrm{CH}_{3} \mathrm{OH}$ ). DFT calculation indicated that the sample possesses an excellent electronic band structure with band-gap energy to be $2.05 \mathrm{eV}$ closed to $2.45 \mathrm{eV}$ obtained from the experiment. The electronic band alignment structure favored a significantly higher $\mathrm{CO}_{2}$ photocatalytic reduction of $0.4 \mu \mathrm{molh}^{-1} \mathrm{~g}^{-1}$ of $\mathrm{CH}_{4}$ and $0.6 \mu \mathrm{molh}^{-1} \mathrm{~g}^{-1}$ of $\mathrm{CH}_{3} \mathrm{OH}$ formation, which is 4.0 and 7.5 times higher than the pure $\mathrm{g}-\mathrm{C}_{3} \mathrm{~N}_{4} \mathrm{NS}$. A combination of nanostructure tuning and doping produced a synergistic effect for enhancing photocatalytic activity and have potential applications in various fields.
\end{abstract}

Keywords: $\mathrm{g}_{-} \mathrm{C}_{3} \mathrm{~N}_{4}$ nanosheets; Br-doping; density functional theory (DFT); solar fuels.

(C) 2021 by the authors. This article is an open-access article distributed under the terms and conditions of the Creative Commons Attribution (CC BY) license (https://creativecommons.org/licenses/by/4.0/).

\section{Introduction}

Over the past three decades, the world has witnessed a tremendous increase in environmental challenges and energy demand caused by the depletion of fossil fuels. To address the challenges above, various technologies have been proposed. Semiconductor photocatalysis is a potential technology proposed to address the challenges mentioned above. This technology involves converting $\mathrm{CO}_{2}$ as a raw material into chemical solar fuels [1-8]. This has necessitated wide and progressive studies into various photocatalytic semiconductor materials over the past decades. However, the major challenges facing the practical application 
of most semiconductor photocatalysts studied and reported are their poor light-harvesting ability in the visible light region and high electron-hole pair recombination rate $[9,3,10]$.

Therefore, in recent times, photocatalysis is a hot research area been explored for metalfree, high efficient, durable, low-cost, and earth-abundant graphitic carbon nitride $\left(\mathrm{g}-\mathrm{C}_{3} \mathrm{~N}_{4}\right)$ semiconductor photocatalyst. $\mathrm{g}-\mathrm{C}_{3} \mathrm{~N}_{4}$ has emerged as a metal-free polymeric semiconductor among the variety of visible light photocatalysts that have been studied extensively due to suitable band-gap $(\sim 2.7 \mathrm{eV})$. It is easily synthesized through thermal condensation of simple and cheap precursors like urea, cyanamide, dicyandiamide, melamine, etc. Also, it has unique physicochemical properties such as high thermal and chemical stability, unique electronic properties, low density, and extreme hardness. These properties make $\mathrm{g}-\mathrm{C}_{3} \mathrm{~N}_{4}$ an excellent potential material for application in a wide range of areas such as photocatalytic $\mathrm{CO}_{2}$ reduction, fuel cells, pollutant removal, photochemical water splitting for hydrogen production, environmental remediation, etc. [1, 3, 9, 11-14]. Nevertheless, serious limitations of pristine g$\mathrm{C}_{3} \mathrm{~N}_{4}$ are its poor visible light utilization ability, fast recombination of photogenerated electronhole pairs (i.e., low mobility of charge carriers), and low surface area [9-11, 15].

Of late, various modification techniques have been explored sufficiently to optimize the performance of $\mathrm{g}-\mathrm{C}_{3} \mathrm{~N}_{4}$. Among them are band-gap engineering, micro/nanostructuring, surface modifications, cocatalyst combination, semiconductor coupling, heterojunction formation, etc. Band-gap engineering through metal and nonmetal elements doping has been studied to inhibit photogenerated electron-hole pairs' recombination and greatly increased the light-harvesting ability in the visible region in pristine $\mathrm{g}-\mathrm{C}_{3} \mathrm{~N}_{4}$. To increase the surface area of g- $\mathrm{C}_{3} \mathrm{~N}_{4}$, various modification strategies including ultrasound exfoliation, chemical exfoliation, chemical oxidation, among others, and morphology nanostructuring through the fabrication of various architectures such as nanotube, hollow sphere, nanofibers, nanowire, nanoribbons, and nanosheet have been explored and observed to be effective [2, 3, 15-20].

Most of the studies carried out to improve the performance of $\mathrm{g}-\mathrm{C}_{3} \mathrm{~N}_{4}$ involved only a single modification technique such as fluorine, iodine, boron, sulfur elemental dopings, etc. [21-26] and morphology tuning [27-29]. Few studies have also reported on the combination of doping and nanostructuring of $\mathrm{g}-\mathrm{C}_{3} \mathrm{~N}_{4}$ for improved photocatalytic activity. For instance, She et al. (2016) reported on the template-free synthesis of 2D porous ultrathin nonmetal-doped g$\mathrm{C}_{3} \mathrm{~N}_{4}$ nanosheets with highly efficient photocatalytic $\mathrm{H}_{2}$ evolution from water under visible light (She et al., 2016). Another study also indicated that simultaneous modification of $g-\mathrm{C}_{3} \mathrm{~N}_{4}$ by co-doping with $\mathrm{S}, \mathrm{P}$, and $\mathrm{O}$ nonmetal-atoms and exfoliation into ultrathin $2 \mathrm{D}$ nanosheets shows significant photocatalytic hydrogen production [30]. Zhou et al. (2019) has also reported that $\mathrm{g}-\mathrm{C}_{3} \mathrm{~N}_{4}$ nanosheets with simultaneous porous network and S-Doping have a remarkable visible-light-driven hydrogen evolution rate [31].

Fabrication of a unique g- $\mathrm{C}_{3} \mathrm{~N}_{4}$ system using multiple modification strategies would largely strengthen the visible light-harvesting ability, charge separation and charge utilization, and surface area simultaneously. Therefore, the photocatalytic performance can be greatly enhanced relative to the single modification strategy. A study by Zhu et al. (2017) based on density functional theory (DFT) calculations shows that halogen-doped monolayer $\mathrm{g}_{-} \mathrm{C}_{3} \mathrm{~N}_{4}$ systems have narrowed band-gap, increased light absorption, and reduced work function which is conducive to high photocatalytic activity [16]. Herein, we report the fabrication of a $\mathrm{Br}$ doped g- $\mathrm{C}_{3} \mathrm{~N}_{4}$ nanosheet for photocatalytic reduction of $\mathrm{CO}_{2}$ into solar fuels (i.e., $\mathrm{CH}_{4}$ and $\mathrm{CH}_{3} \mathrm{OH}$ ). In detail, analyses of optical absorption, surface area, intrinsic band structure, and charge transfer are carried out to examine Br-doping's effects in the nanosheet of $\mathrm{g}-\mathrm{C}_{3} \mathrm{~N}_{4}$ 
matrices for visible-light photocatalytic activity. To better understand the effect of $\mathrm{Br}$ doping on the electronic structure of g-C3N4 nanosheet, Density Functional Theory (DFT) calculations were carried out using a model unit.

\section{Materials and Methods}

\subsection{Preparation of Br-doped g-C3N4 nanosheet.}

$2.0 \mathrm{~g}$ of dicyandiamide was mixed with $1.0 \mathrm{~g}$ of ammonium bromide $\left(\mathrm{NH}_{4} \mathrm{Br}\right)$ in $10 \mathrm{ml}$ deionized water. The mixture was stirred at $80^{\circ} \mathrm{C}$ to remove water and dry in an oven. The resultant solid was calcined at $550^{\circ} \mathrm{C}$ at $5^{\circ} \mathrm{C} \min ^{-1}$ for $4 \mathrm{~h}$ in $\mathrm{N}_{2}$ gas atmosphere in a tube furnace to obtain the final bulk sample. The bulk sample obtained was ground into a fine powder and exfoliated in methanol by ultrasonication for $48 \mathrm{~h}$ to obtain a Br-doped $\mathrm{g}-\mathrm{C}_{3} \mathrm{~N}_{4}$ nanosheet. Pristine nanosheet $\mathrm{g}-\mathrm{C}_{3} \mathrm{~N}_{4}$ was prepared without the addition of $\mathrm{NH}_{4} \mathrm{Br}$.

\subsection{Characterization.}

Powder X-ray diffraction (XRD) was conducted on an X-ray diffractometer (Rigaku, Japan) using $\mathrm{Cu} \mathrm{K \alpha}$ irradiation $(\lambda=0.15418 \mathrm{~nm})$ at a scan rate of $0.05^{\circ} \mathrm{s}^{-1}$. Transmission electron microscopy (TEM) analysis was conducted using a Tecnai $\mathrm{G}^{2} 20 \mathrm{U}$-Twin electron microscope. The element mapping and field emission scanning electron microscopy were performed using the FESEM Hitachi S-4800 instrument, connected with energy-dispersive X-ray spectroscopy (EDS, Oxford Instruments, Britain). The thickness of the samples was measured by AFM (Multimode 8, Bruker, USA). The Brunauer-Emmett-Teller (BET) specific surface areas $\left(S_{B E T}\right)$ of the samples were determined by nitrogen adsorption data obtained in a Micromeritics ASAP 2020 nitrogen adsorption apparatus (USA). All the samples were degassed at $180{ }^{\circ} \mathrm{C}$ before the nitrogen adsorption measurements. A desorption isotherm was used to determine the pore size distribution via the Barret-Joyner-Halender $(\mathrm{BJH})$ method, assuming a cylindrical pore modal. The nitrogen adsorption volume at the relative pressure $\left(P / P_{0}\right)$ of 0.994 was used to calculate the pore volume and average pore size [32]. The XPS measurement was performed in an ultrahigh vacuum VGESCALAB 210 electron spectrometer equipped with a multichannel detector, using $\mathrm{Mg} \mathrm{K \alpha}(1253.6 \mathrm{eV})$ radiation (operated at $200 \mathrm{~W}$ ) of a twin anode in the constant analyzer energy mode with a pass energy of $30 \mathrm{eV}$. All the binding energies were referenced to the $\mathrm{C} 1 \mathrm{~s}$ peak at $284.8 \mathrm{eV}$ of the surface adventitious carbon. Survey scans and detailed scans of $\mathrm{C} 1 \mathrm{~s}$ and $\mathrm{N} 1 \mathrm{~s}$ photoelectron peaks were recorded for the samples. The samples' optical absorption property was obtained by a UV-visible absorption spectrophotometer (UV2600, Shimadzu, Japan). $\mathrm{BaSO}_{4}$ was used as a reflectance standard in the UV-visible reflectance experiment. Fourier transform infrared spectra (FT-IR) of the samples were evaluated using an IR Affinity-1 FT-IR spectrometer which uses conventional KBr pellets in the range of $4000-500 \mathrm{~cm}^{-1}$ at room temperature. Photoluminescence (PL) emission spectra were used to investigate the fate of photogenerated electrons and holes in the samples. It was measured at room temperature on an F-7000 Fluorescence Spectrophotometer (Hitachi, Japan). The excitation wavelength was $380 \mathrm{~nm}$, the scanning speed was $1200 \mathrm{~nm} \mathrm{~min}{ }^{-1}$, and the photomultiplier tube (PMT) voltage was $700 \mathrm{~V}$. The width of both the excitation slit and the emission slit was $1.0 \mathrm{~nm}$. Time-resolved transient PL decay curves were obtained from an FLS920 fluorescence lifetime spectrophotometer (Edinburgh Instruments, UK) under the excitation of $325 \mathrm{~nm}$. 


\subsection{Photocatalytic CO2 reduction test.}

According to our recent reports, the photocatalytic reduction of $\mathrm{CO}_{2}$ was carried out in a $200 \mathrm{~mL}$ capacity home-made Pyrex reactor at room temperature and atmospheric pressure, according to our recent reports [28]. In a typical photocatalytic $\mathrm{CO}_{2}$ reduction experiment, 0.1 $\mathrm{g}$ of the sample was suspended in $20 \mathrm{~mL}$ of deionized water, ultra-sonicated, and dried in an oven at $80{ }^{\circ} \mathrm{C}$ to form a thin film at the bottom of the Pyrex reactor. Before illumination, the reactor was tightly sealed and fastened using a rubber septum. Then, ultra-pure nitrogen gas was blown through the system for $30 \mathrm{~min}$ to remove air and to create an anaerobic condition in the reaction system. There was a chemical reaction between $0.12 \mathrm{~g} \mathrm{NaHCO}_{3}$ (added into the reactor before sealing) and $0.3 \mathrm{~mL} \mathrm{HCl}$ aqueous solution $(4 \mathrm{M})$, which was added into the reactor by syringe to produce $\mathrm{CO}_{2}$ and $\mathrm{H}_{2} \mathrm{O}$ vapor in-situ. Then, the reactor was irradiated for $1 \mathrm{~h}$ under visible light by a 300-W Xe arc lamp with UV-cut off filter $(\lambda>400 \mathrm{~nm})$, which was placed $10 \mathrm{~cm}$ above the photocatalytic reactor. After photocatalytic $\mathrm{CO}_{2}$ reduction reaction, 1 $\mathrm{mL}$ of mixed gas was taken out from the reactor and examined using a gas chromatograph (GC2014C, Shimadzu, Japan) equipped with a flame ionized detector (FID) and methanizer. Products were analyzed based on retention time data for the analyte and the standard gaseous sample. The amount of $\mathrm{CH}_{4}$ and $\mathrm{CH}_{3} \mathrm{OH}$ produced after the reaction was quantified as major products of the reaction.

\subsection{Photoelectrochemical measurements.}

The electrochemical behaviors of the as-prepared samples were determined by Electrochemical Impedance Spectroscopy (EIS) and transient photocurrent measurements. Before the EIS and photocurrent measurements, the samples were prepared as the working electrodes as follows: $0.08 \mathrm{~g}$ of the samples were grounded with $0.03 \mathrm{~g}$ of polyethylene glycol (PEG, molecular weight: 20000) and $0.5 \mathrm{~mL}$ of ethanol to make a slurry. The slurry was then coated on a $2 \mathrm{~cm}$ x $1.5 \mathrm{~cm}$ fluorine-tin oxide (FTO) glass electrode by the doctor blade technique. Next, the prepared electrodes were dried and then calcined at $450^{\circ} \mathrm{C}$ for $1 \mathrm{~h}$ in an oven at a heating rate of $5{ }^{\circ} \mathrm{C} \mathrm{min}{ }^{-1}$. The weight and thickness of the sample coated on the FTO glass were fixed at ca. $10 \mathrm{mg}$ and $15 \mathrm{~mm}$, respectively. The photoelectrochemical measurements were performed in a three-electrode system $(\mathrm{CH} 1660 \mathrm{C}$ instruments, CHI. China) using $\mathrm{Ag} / \mathrm{AgCl}$ as the reference electrode, $\mathrm{Pt}$ wire as the counter electrode, and sample coated FTO glass as the working electrode (with an active area of ca. $\left.0.5 \mathrm{~cm}^{2}\right) . \mathrm{Na}_{2} \mathrm{SO}_{4}(0.5$ $\mathrm{M})$ aqueous solution was used as the electrolyte. EIS measurements were obtained from the Nyquist plot carried out. However, for the photocurrent measurements, an LED light (3 W, 420 $\mathrm{nm}$, Shenzhen LAM-PLIC Science Co. Ltd, China) was positioned $1 \mathrm{~cm}$ away from the reactor and was used as a visible-light source. The measurements obtained were used to plot the photocurrent-time ( $(-t)$ curves. Mott-Schottky plots were measured in $0.5 \mathrm{M} \mathrm{Na}_{2} \mathrm{SO}_{4}$ solution at ambient temperature. The potential range was -1.0 to $2.0 \mathrm{~V}$ and at different frequencies of 1 , 2 , and $3 \mathrm{kHz}$ with an $\mathrm{AC}$ voltage magnitude of $10 \mathrm{mV}$ and a scan rate of $10 \mathrm{mV} \mathrm{s}^{-1}$.

\subsection{DFT computational method.}

In this work, ab initio calculations within the density functional theory (DFT) method using the plane-wave basis sets implemented in the Quantum Espresso code [33] has been employed. The generalized gradient approximation in the Perdew, Burke, and Ernzerhof (GGA-PBE) format and the Grimme van der Waals (vdW) dispersion correction as a necessary 
tool to account for the adverse effects of dispersion forces is employed in our model structural material as proposed by Tkatchenko and Scheffler (TS method). We use the ultrasoft pseudopotentials [34] in modeling the interactions between the ions and electrons with PerdewBurke-Ernzerhof (PBE) exchange-correlation functional [35]. The Methfessel-Paxton smearing technique is used to smear occupation numbers with Gaussian broadening of up to 0.001 Ry [36].

A plane wave energy cutoff of 30 Ryd was used, and periodic boundary conditions are applied. The unit cell is oriented along with the z-axis and unit cell geometry with a vacuum space of $12 \AA$ thick in both $\mathrm{x}$ - and y-directions are allowed to ensure negligible interactions between the structure and its periodic images with a unit cell lattice parameter of $6.987 \AA$. The structure is optimized with the Broyden-Fletcher Goldfarb-Shanno (BFGS) method [37]. Next, we sample with a $\Gamma$-centred 5x5x1 Monkhorst-Pack scheme [38] grid for the k-points generation along the high-symmetry paths of $\Gamma-\mathrm{M}-\mathrm{K}-\mathrm{L}-\Gamma$ in the irreducible Brillouin zone to acquire the band structures with very smooth grid for our mesh points. fine $9 \times 9 \times 1$ grids follow this for non-self-consistent field (NSCF) calculations to determine quantized energy levels and Fermi energy for band structure calculations, charge density analysis, the density of electronic states (DOS), and partial density of electronic states (PDOS).

\section{Results and Discussion}

\subsection{Structure and morphology characterization.}

Figure 1. shows the XRD patterns of the crystal structure of the samples prepared. The successful exfoliation of bulk $\mathrm{g}-\mathrm{C}_{3} \mathrm{~N}_{4}$ into nanosheets was indicated by the significant decrease in the peak intensities at (001) and (002) planes (Figure 1A). From Figure 1(B), the strong peak at 27.30 indicates the (002) interlayer diffraction stacking for graphitic materials [31, 30]. No other peak was observed in the XRD patterns to show bromine because of its low concentration used in the samples' preparation. The SEM images of the Br-doped g- $\mathrm{C}_{3} \mathrm{~N}_{4}$ nanosheets show a thin-layered structure indicating the effectiveness of the exfoliation process employed in the study (Figure 2). Also, the TEM image revealed the very thin thickness and almost the transparent nature of the Br-doped g- $\mathrm{C}_{3} \mathrm{~N}_{4}$ nanosheet (Figure 3). The atomic force microscopy (AFM) analysis was carried out further to investigate the structural features of the Br-doped $\mathrm{g}-\mathrm{C}_{3} \mathrm{~N}_{4}$ nanosheets. It can be observed that the thickness of the Br-doped $\mathrm{g}-\mathrm{C}_{3} \mathrm{~N}_{4}$ was approximately $4.0 \mathrm{~nm}$, an indication that the exfoliated nanosheets comprised of 9-11 C-N atomic monolayers (Figure 4).

From the EDX elemental mapping images (Figure 5), it can be observed that only carbon $(\mathrm{C})$ and nitrogen $(\mathrm{N})$ were the elements homogeneously distributed as components within the Br-doped $\mathrm{g}_{-} \mathrm{C}_{3} \mathrm{~N}_{4}$ nanosheets. This was also indicated by the EDX composition graph (Fig. 5). Br was not detected because of its low concentration used in the preparation of the sample. The $\mathrm{C} / \mathrm{N}$ molar ratio of $\mathrm{Br}$-doped $\mathrm{g}-\mathrm{C}_{3} \mathrm{~N}_{4}(0.5 \mathrm{~g})$ and pure $\mathrm{g}-\mathrm{C}_{3} \mathrm{~N}_{4}$ nanosheet was determined to be 0.76 and 0.74 , respectively. The stoichiometric $\mathrm{C}: \mathrm{N}$ ratios were $\mathrm{C}_{2.6}: \mathrm{N}_{3.4}$ and $\mathrm{C}_{3.1}: \mathrm{N}_{4.2}$ for Br-doped $\mathrm{g}-\mathrm{C}_{3} \mathrm{~N}_{4}$ and pure $\mathrm{g}-\mathrm{C}_{3} \mathrm{~N}_{4}$ nanosheet, respectively. The variation in the ratios obtained from the hypothetical value of 0.75 for the ideal $g-\mathrm{C}_{3} \mathrm{~N}_{4}$ indicates incomplete condensation, which is associated with the preparation of $\mathrm{g}-\mathrm{C}_{3} \mathrm{~N}_{4}$ [28]. 

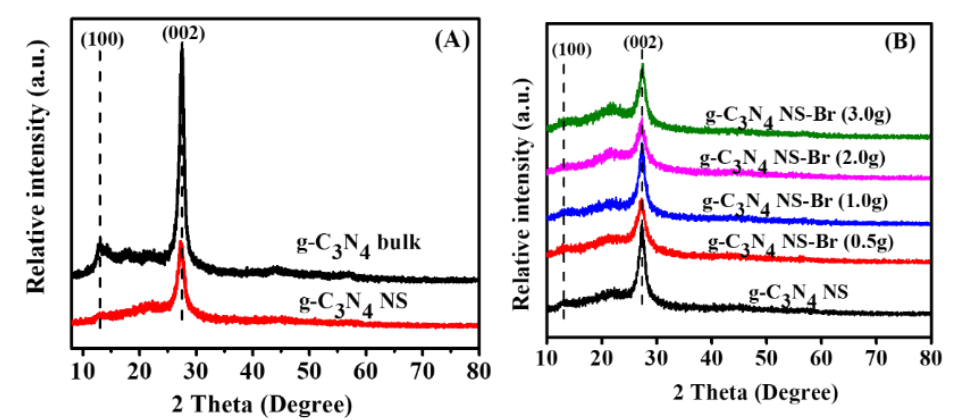

Figure 1. XRD patterns (a) bulk and nanosheet $\mathrm{g}-\mathrm{C}_{3} \mathrm{~N}_{4}$ nanosheets (b) pure and Br-doped $\mathrm{g}-\mathrm{C}_{3} \mathrm{~N}_{4}$ nanosheets.

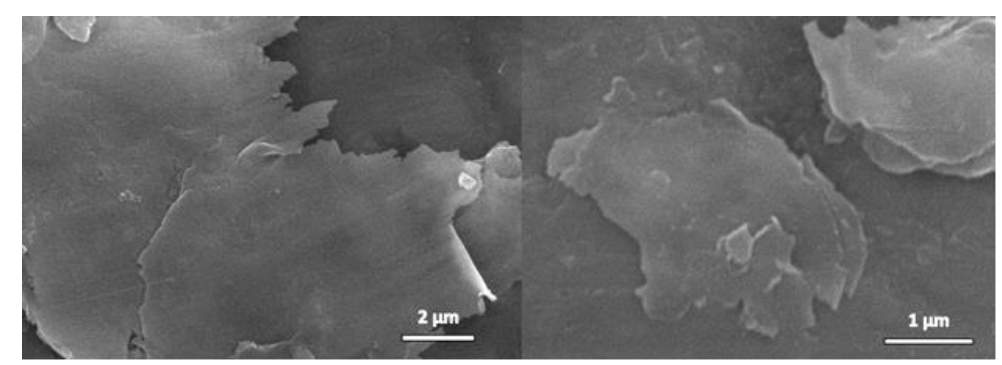

Figure 2. $\mathrm{SEM}$ of $\mathrm{Br}$-doped $\mathrm{g}-\mathrm{C}_{3} \mathrm{~N}_{4}(0.5 \mathrm{~g})$ nanosheets

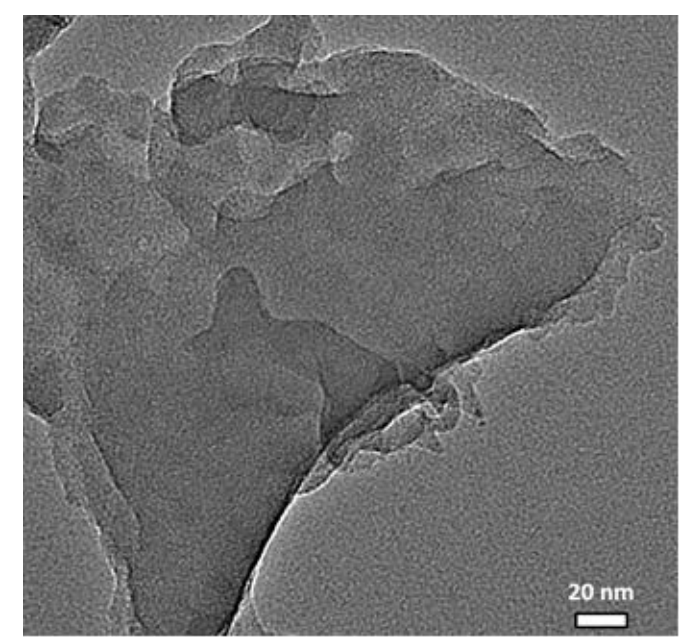

Figure 3. TEM of Br-doped $\mathrm{g}-\mathrm{C}_{3} \mathrm{~N}_{4}(0.5 \mathrm{~g})$ nanosheet.
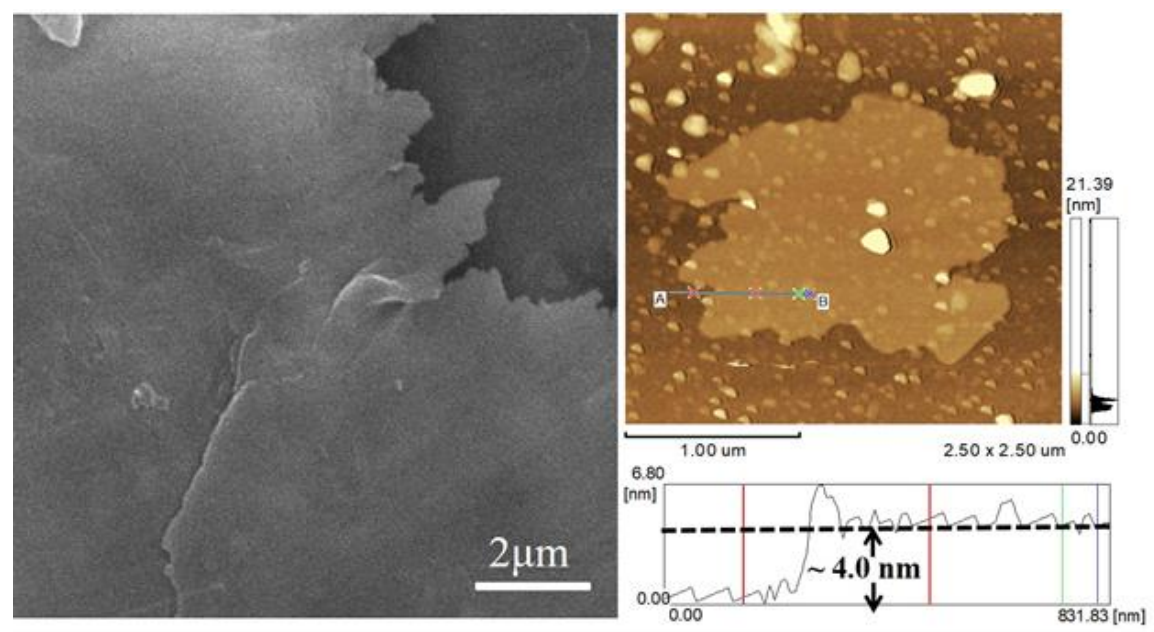

Figure 4. AFM images of $\mathrm{Br}-$ doped $\mathrm{g}-\mathrm{C}_{3} \mathrm{~N}_{4}(0.5 \mathrm{~g})$ nanosheet. 


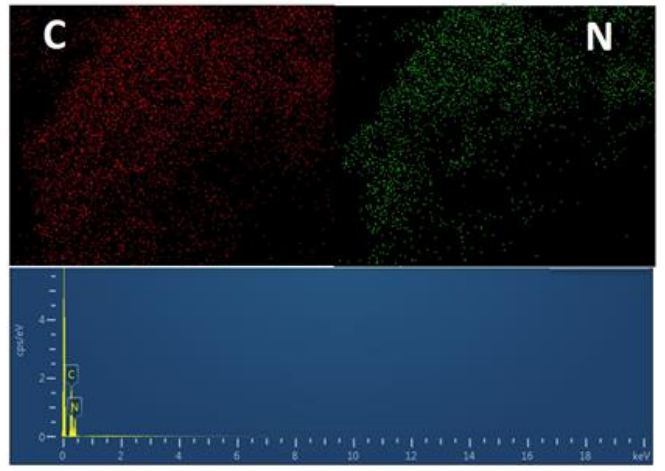

Figure 5. EDX images and composition graph of Br-doped $\mathrm{g}-\mathrm{C}_{3} \mathrm{~N}_{4}(0.5 \mathrm{~g})$ nanosheet.

The samples' atomic bond structure was further analyzed by the Fourier transform infrared (FTIR) spectroscopy, as shown in Fig 6. The samples' characteristics absorption peaks at $1215-1640 \mathrm{~cm}^{-1}$ and $811 \mathrm{~cm}^{-1}$ were attributed to the vibration mode of aromatic C-N heterocycles and breathing vibration of triazine (or heptazine) units, respectively. The broad absorption peak located at $3000-3500 \mathrm{~cm}^{-1}$ was attributed to the $\mathrm{O}-\mathrm{H}$ or $\mathrm{N}-\mathrm{H}$ stretching vibration mode of $\mathrm{N}-\mathrm{H}$ bond in $\mathrm{CN}$, as well as the surface adsorbed $\mathrm{OH}[28,31,39]$. The characteristic vibration peaks of bromine-related groups were not detected in any of the $\mathrm{Br}$ doped $\mathrm{g}-\mathrm{C}_{3} \mathrm{~N}_{4}$ nanosheet samples, indicating that $\mathrm{Br}$ did not affect $\mathrm{CN}$ 's crystal phase. This might be due to the low bromine content used in the preparation of the samples.

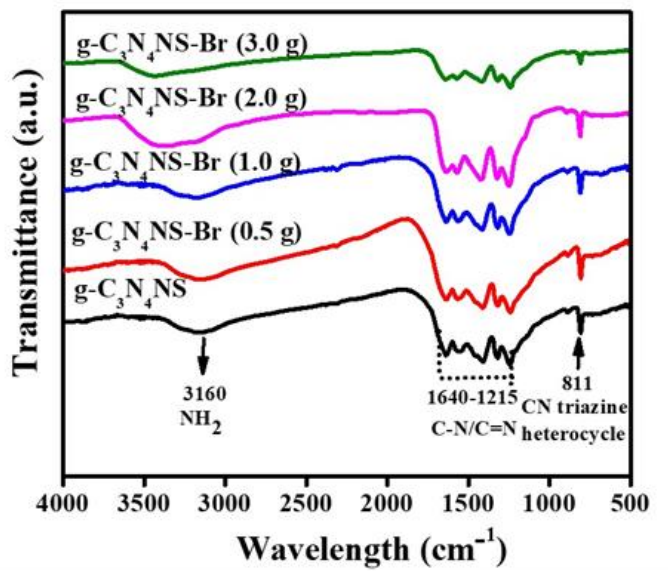

Figure 6. FTIR of pure g- $\mathrm{C}_{3} \mathrm{~N}_{4}$ nanosheets and Br-doped g- $\mathrm{C}_{3} \mathrm{~N}_{4}$ nanosheets.

To characterize the specific surface areas and porosity of samples, the $\mathrm{N}_{2}$ adsorptiondesorption isotherm and pore size analysis were carried out. From Figure 7, it can be observed that all the samples exhibited type IV shapes of isotherms (BDDT classification) with an $\mathrm{H}_{3}$ type hysteresis loop in the IUPAC classification. This suggests the existence of slit-like mesopores inside the samples because of the accumulation of plate-like particles. This result is in line with the morphology of the nanosheets obtained, as shown by the SEM and TEM (Fig. 2 and 3). It can be seen further that the isotherms exhibited a high relative pressure range (approaching 1.0), an indication of the presence of mesopores and macropores. The mesoporosity of the samples was further confirmed by the pore distribution curves, which are from 4 to $120 \mathrm{~nm}$ (inset in Figure 7). The samples show the mesopores' existence at a peak pore size of $4 \mathrm{~nm}$ and macropores at $75 \mathrm{~nm}$. The mesopores and macropores may be formed during the thermal exfoliation process of splitting the large or bulk $\mathrm{g}-\mathrm{C}_{3} \mathrm{~N}_{4}$ layers into thin nanosheets. 


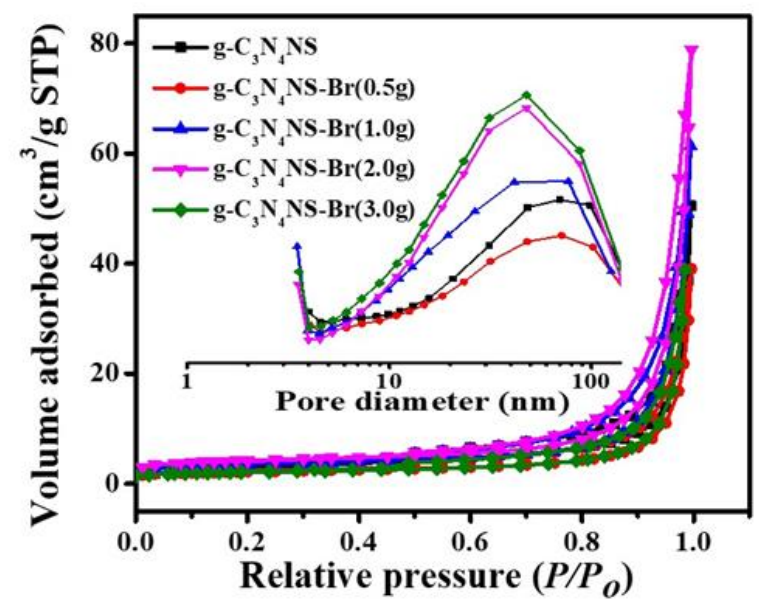

Figure 7. $\mathrm{N}_{2}$ adsorption-desorption isotherms and the corresponding pore size allocation curves of the asprepared samples are shown as insert.

The specific BET surface area, pore-volume, and peak pore size are summarized in Table 1. It can be observed that the surface area and pore sizes of the samples increases as the bromine concentration also increases. Generally, the samples' surface areas and pore sizes are large, which would result in efficient surface absorption of reactants and faster-photogenerated carrier separation leading to improve photocatalytic activity.

Table 1. Physical properties of the samples.

\begin{tabular}{l|c|c|c} 
Samples & $\begin{array}{c}\text { SBET } \\
(\mathbf{m} 2 / \mathbf{g})\end{array}$ & $\begin{array}{c}\text { Pore volume } \\
(\mathbf{c m} 3 / \mathbf{g})\end{array}$ & $\begin{array}{c}\text { Pore size } \\
(\mathbf{n m})\end{array}$ \\
\hline $\mathrm{g}-\mathrm{C}_{3} \mathrm{~N}_{4} \mathrm{NS}$ & 10.5 & 0.03 & 12.3 \\
\hline $\mathrm{g}-\mathrm{C}_{3} \mathrm{~N}_{4} \mathrm{NS}-\mathrm{Br}(0.5 \mathrm{~g})$ & 0.4 & 0.001 & 14.6 \\
\hline $\mathrm{g}-\mathrm{C}_{3} \mathrm{~N}_{4} \mathrm{NS}-\mathrm{Br}(1.0)$ & 7.6 & 0.03 & 13.7 \\
\hline $\mathrm{g}-\mathrm{C}_{3} \mathrm{~N}_{4} \mathrm{NS}-\mathrm{Br}(2.0 \mathrm{~g})$ & 12.1 & 0.05 & 16.2 \\
\hline $\mathrm{g}-\mathrm{C}_{3} \mathrm{~N}_{4} \mathrm{NS}-\mathrm{Br}(3.0)$ & 14.7 & 0.06 & 16.5
\end{tabular}

\subsection{Chemical characterization.}

To investigate the composition of the chemical state of the samples prepared, X-ray photoelectron spectroscopy (XPS) analysis was carried out. The XPS survey spectrum shown in Figure 8(a) indicated only three elements (i.e., C, N, and O). No prominent peak can be found signaling the presence of bromine due to the low concentration of $\mathrm{Br}$ ions used in the preparation of the samples. The peak representing the $\mathrm{O} 1 \mathrm{~s}$ is due to absorbed $\mathrm{H}_{2} \mathrm{O}$ or $\mathrm{CO}_{2}$ molecules on the samples' surface and confirmed by the FTIR analysis. The high-resolution $\mathrm{C}$ 1s spectra (Figure 8b) of the samples can be deconvoluted into two peaks located at $284.8 \mathrm{eV}$ and $288.1 \mathrm{eV}$ binding energies ascribed to surface adventitious carbon derived from the XPS instrument itself and sp2 hybridized carbon-carbon (C-C) bonds and in the sp2-hybridized carbon-nitrogen of the aromatic ring $(\mathrm{N}-\mathrm{C}=\mathrm{N})$, respectively [28, 30, 40]. The high-resolution spectra of $\mathrm{N} 1 \mathrm{~s}$ shown in Fig. 8(C) were deconvoluted into four peaks located at $398.8 \mathrm{eV}$ for $\mathrm{C}-\mathrm{N}=\mathrm{C}, 399.2 \mathrm{eV}$ for $\mathrm{C}_{3}-\mathrm{N}, 401.0 \mathrm{eV}$ for $\mathrm{N}-\mathrm{H}$ and $404.3 \mathrm{eV}$ for $\pi-\pi$ excitation $[40,41]$. The high-resolution spectra of $\mathrm{Br} 3 \mathrm{~d}$ show a very weak and small broad peak located in a range of $67.7 \mathrm{eV}$ and $69.2 \mathrm{eV}$, as shown in Fig. 8(d). This weak peak is due to the low concentration of bromine used in the sample preparation and attributed to bromine bonded to carbon (i.e., $\mathrm{Br}$ atoms interacted with the C-N network) [42, 43]. 

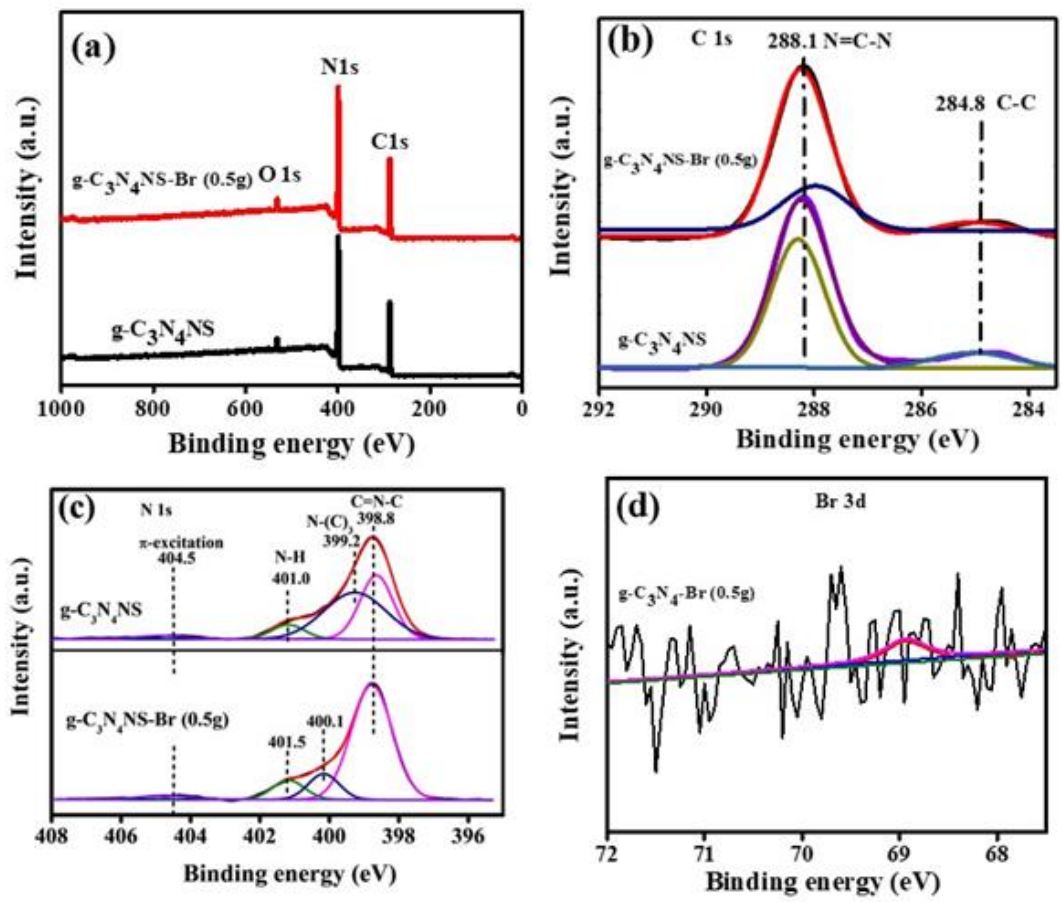

Figure 8. Survey spectrum (a) and the corresponding high-resolution spectra of C1s (b), N1s (c), N 1s (d) Br 3d of the pure $\mathrm{g}-\mathrm{C}_{3} \mathrm{~N}_{4}$ nanosheet and $\mathrm{Br}$-doped $\mathrm{g}-\mathrm{C}_{3} \mathrm{~N}_{4}$ nanosheets samples.

\subsection{Optical property.}

The light-harvesting or optical properties of the samples were investigated by UV-vis diffuse reflectance spectroscopy (DRS). It can be observed from Figure 9 that all the samples show similarities in their absorption spectra extending from the UV region to the visible region up to approximately $700 \mathrm{~nm}$. However, the Br-doped $\mathrm{g}-\mathrm{C}_{3} \mathrm{~N}_{4} \mathrm{NS}$ samples exhibited slight changes in the absorption edge and hence band-gap energies due to the doping effect of the bromide ion and color variations (shown as an insert in Fig. 9). The dopant has enhanced the samples' light-harvesting ability, causing a slight blue shift in the wavelength of pure $\mathrm{g}-\mathrm{C}_{3} \mathrm{~N}_{4}$ NS from $495 \mathrm{~nm}$ to around $505 \mathrm{~nm}$ in the bromine doped samples. This is an indication of an improvement in the band-gap energy. It can be observed specifically in Figure 10 that the g$\mathrm{C}_{3} \mathrm{~N}_{4} \mathrm{NS}-\mathrm{Br}(0.5 \mathrm{~g})$ sample have band-gap energy of $2.45 \mathrm{eV}$ whiles that of pure $\mathrm{g}-\mathrm{C}_{3} \mathrm{~N}_{4} \mathrm{NS}$ was $2.51 \mathrm{eV}$; a difference of $0.06 \mathrm{eV}$, which could be attributed to the nanostructuring or tuning of $\mathrm{g}-\mathrm{C}_{3} \mathrm{~N}_{4}$ into nanosheets and the bromine doping effects.

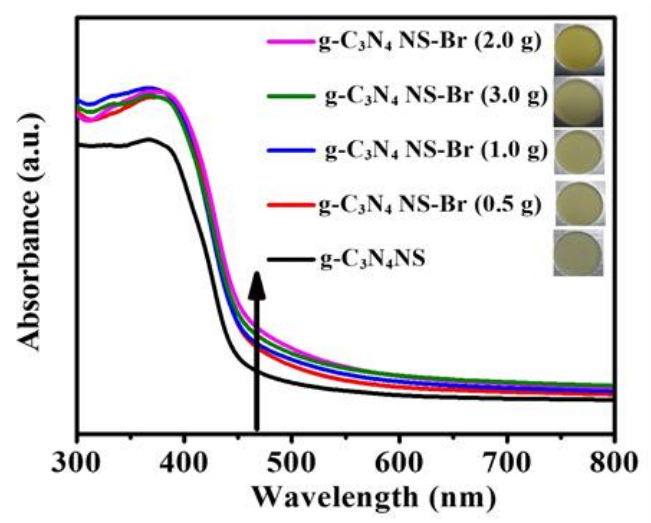

Figure 9. (a) UV-vis diffuse reflectance spectra of pure g-C3N4 nanosheets and $\mathrm{Br}-\mathrm{doped} g-\mathrm{C}_{3} \mathrm{~N}_{4}$ nanosheets. 


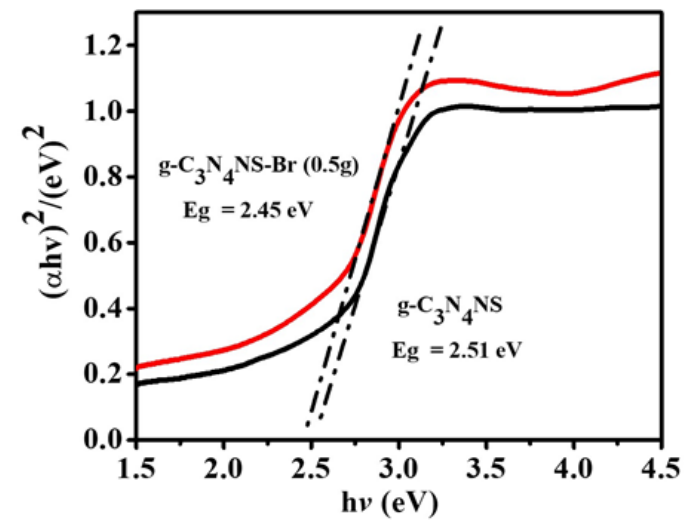

Figure 10. Kubelka-Munk band-gap energies of pure $g-\mathrm{C}_{3} \mathrm{~N}_{4}$ nanosheets and $\mathrm{Br}$-doped g- $\mathrm{C}_{3} \mathrm{~N}_{4}$ nanosheets $(0.5 \mathrm{~g})$ samples.

To gain further insight into the charge carrier separation, which is a pre-requisite for effective photocatalytic activity, photoluminescence (PL) emission spectroscopy was carried out. This analysis determines the charge carrier's dissolution or re-sequencing rate of photogenerated electrons and holes pairs of the photocatalyst. If the PL peak intensity is stronger, it indicates the superior re-sequencing ability of the photoexcited electron-hole pairs and hence lower photocatalytic activity [28]. Figure 11 shows the samples' PL spectra with g$\mathrm{C}_{3} \mathrm{~N}_{4} \mathrm{NS}-\mathrm{Br}(0.5 \mathrm{~g})$ exhibiting a decreased PL intensity and stronger PL quenching relative to other samples, the pure $\mathrm{g}-\mathrm{C}_{3} \mathrm{~N}_{4} \mathrm{NS}$. This is attributed to the synergistic effect of the nanosheets formed and Br-doping, which led to efficient suppression in the re-sequencing rate of photoexcited electron-hole pairs. Therefore, the effective separation of charge transfers in the g- $\mathrm{C}_{3} \mathrm{~N}_{4} \mathrm{NS}-\mathrm{Br}(0.5 \mathrm{~g})$ sample enhances the sample's photocatalytic activity.

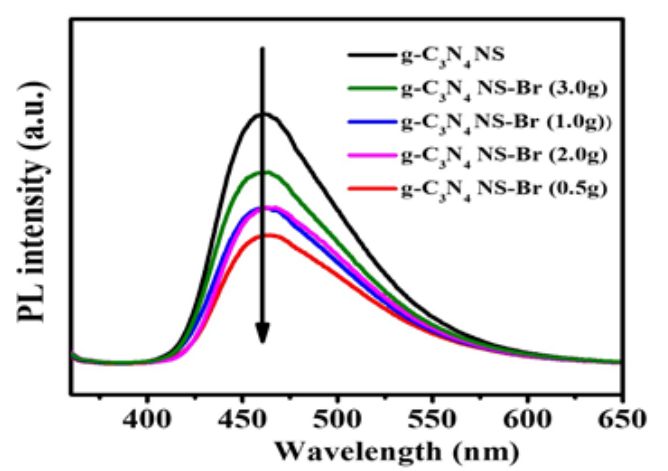

Figure 11. PL spectra of pure g- $\mathrm{C}_{3} \mathrm{~N}_{4}$ nanosheet and Br-doped $\mathrm{g}-\mathrm{C}_{3} \mathrm{~N}_{4}$ nanosheets samples.

To further investigate the charge carrier recombination dynamics, the time-resolved fluorescence decay analysis was carried out. It can be observed from Figure 12 that both the short and long lifetime $(\tau)$ values of $\mathrm{g}-\mathrm{C}_{3} \mathrm{~N}_{4} \mathrm{NS}-\mathrm{Br}(0.5 \mathrm{~g})$ were much higher than that of pure $\mathrm{g}-\mathrm{C}_{3} \mathrm{~N}_{4}$ NS. This suggests that the charge lifetime of $\mathrm{g}-\mathrm{C}_{3} \mathrm{~N}_{4} \mathrm{NS}-\mathrm{Br}(0.5 \mathrm{~g})$ sample was significantly prolonged due to $\mathrm{Br}$ doping and quantum confinement effects in the constructed nanosheets [40]. This has improved the electron-hole separation efficiency and increased the probability of charge carrier's involvement in photocatalytic reaction before re-sequencing or recombination. 


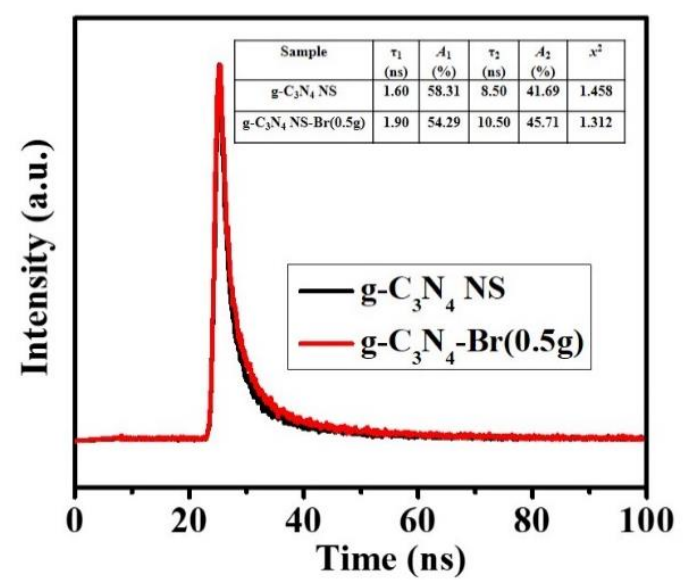

Figure 12. Time-resolved transient fluorescence decay curves of pure $g-\mathrm{C}_{3} \mathrm{~N}_{4}$ nanosheet and doped g- $\mathrm{C}_{3} \mathrm{~N}_{4} \mathrm{NS}-$ $\mathrm{Br}(0.5 \mathrm{~g})$ samples excited at the wavelength of $325 \mathrm{~nm}$.

Electrochemical Impedance Spectroscopy (EIS) was carried out to further understand and provide more information on the recombination rate of photoexcited electron-hole pairs (i.e., charge carriers separation efficiency). From the Nyquist plots shown in Fig. 13, it can be observed that $\mathrm{g}-\mathrm{C}_{3} \mathrm{~N}_{4} \mathrm{NS}-\mathrm{Br}(0.5 \mathrm{~g})$ sample has shown a remarkably very low semicircle arc relative to the other samples. This indicates a lower recombination rate of photoexcited electron-hole pairs (i.e., inhibition in the rearrangement of photogenerated electron and hole pairs), resulting in higher migration of charge carriers and favorable to effective photocatalytic performance. However, samples with large semicircle arcs, especially the pure $\mathrm{g}_{-} \mathrm{C}_{3} \mathrm{~N}_{4} \mathrm{NS}$ can be attributed to faster recombination or rearrangement of photogenerated electrons and hole pairs.

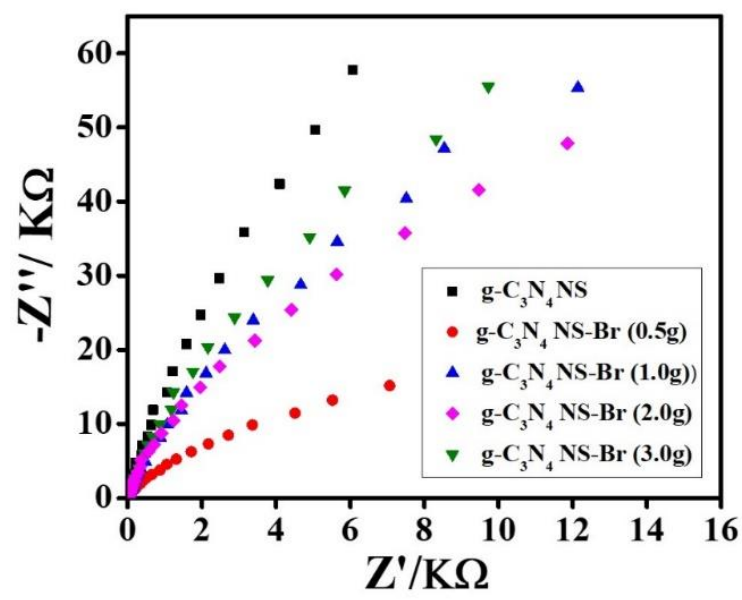

Figure 13. Nyquist plots of pure $g-C_{3} N_{4}$ nanosheet and Br-doped g- $C_{3} N_{4}$ nanosheets samples.

To determine the suitability of the $\mathrm{g}_{-} \mathrm{C}_{3} \mathrm{~N}_{4} \mathrm{NS}-\mathrm{Br}(0.5 \mathrm{~g})$ for photocatalytic $\mathrm{CO}_{2}$ reduction into solar fuels under visible light irradiation, Mott-Schottky analysis was carried out to examine the band energy level structure. The electrochemical technique was used to measure the flat band potential $\left(E_{F B}\right)$ to estimate the approximate conduction band edge potentials $\left(E_{C B}\right)$. It can be observed from the Mott-Schottky plots that the samples g- $\mathrm{C}_{3} \mathrm{~N}_{4} \mathrm{NS}$ and $g-\mathrm{C}_{3} \mathrm{~N}_{4} \mathrm{NS}-$ $\operatorname{Br}(0.5 \mathrm{~g})$ show positive slopes, which is a typical characteristic of an n-type semiconductor. This is an indication that the majority of the charge carriers are electrons [28]. From the MottSchottky plots, the conduction band potentials $\left(E_{C B}\right)$ were $-1.22 \mathrm{~V}$ and $-1.31 \mathrm{~V}$ for $\mathrm{g}-\mathrm{C}_{3} \mathrm{~N}_{4} \mathrm{NS}$ and $\mathrm{g}-\mathrm{C}_{3} \mathrm{~N}_{4} \mathrm{NS}-\mathrm{Br}(0.5 \mathrm{~g})$ samples, respectively (Figure 14(a)). Based on the band-gap energies 
(Eg) derived from the Tauc plots of the Kubelka-Munk function (Fig.10), the valence band potentials $\left(E_{V B}\right)$ were determined from the formula $\mathrm{E}_{\mathrm{CB}}=\mathrm{EVB}-\mathrm{Eg}$ for $\mathrm{g}-\mathrm{C}_{3} \mathrm{~N}_{4} \mathrm{NS}$ and g- $\mathrm{C}_{3} \mathrm{~N}_{4}$ NS-Br $(0.5 \mathrm{~g})$ samples to be $1.29 \mathrm{~V}$ and $1.14 \mathrm{~V}$, respectively. The schematic band energy level alignment (Fig 14(b)) shows that both g- $\mathrm{C}_{3} \mathrm{~N}_{4} \mathrm{NS}$ and $\mathrm{g}-\mathrm{C}_{3} \mathrm{~N}_{4} \mathrm{NS}-\mathrm{Br}(0.5 \mathrm{~g})$ samples satisfied the condition for photocatalytic reduction of $\mathrm{CO}_{2}$ into solar fuels thermodynamically. It could also be seen from Figure 14(b) that the CB edge of $\mathrm{g}-\mathrm{C}_{3} \mathrm{~N}_{4} \mathrm{NS}-\mathrm{Br}(0.5 \mathrm{~g})$ has shifted to more negative potential while that of $\mathrm{VB}$ edge shifts to less positive values compared to pure $\mathrm{g}-\mathrm{C}_{3} \mathrm{~N}_{4}$ NS. Generally, the more negative the CB value, the decreased photoexcited electrons are produced and transferred to reactants for a reaction. This is coupled with a lower recombination rate because of efficient charge carriers' better transportability [28]. Upon visible light irradiation, $\mathrm{g}-\mathrm{C}_{3} \mathrm{~N}_{4} \mathrm{NS}-\mathrm{Br}(0.5 \mathrm{~g})$ has a more favored electronic band alignment structure and stronger reducing power for reactants for enhanced photocatalytic performance due to the synergistic effect of the nanosheets constructed and bromine doping.
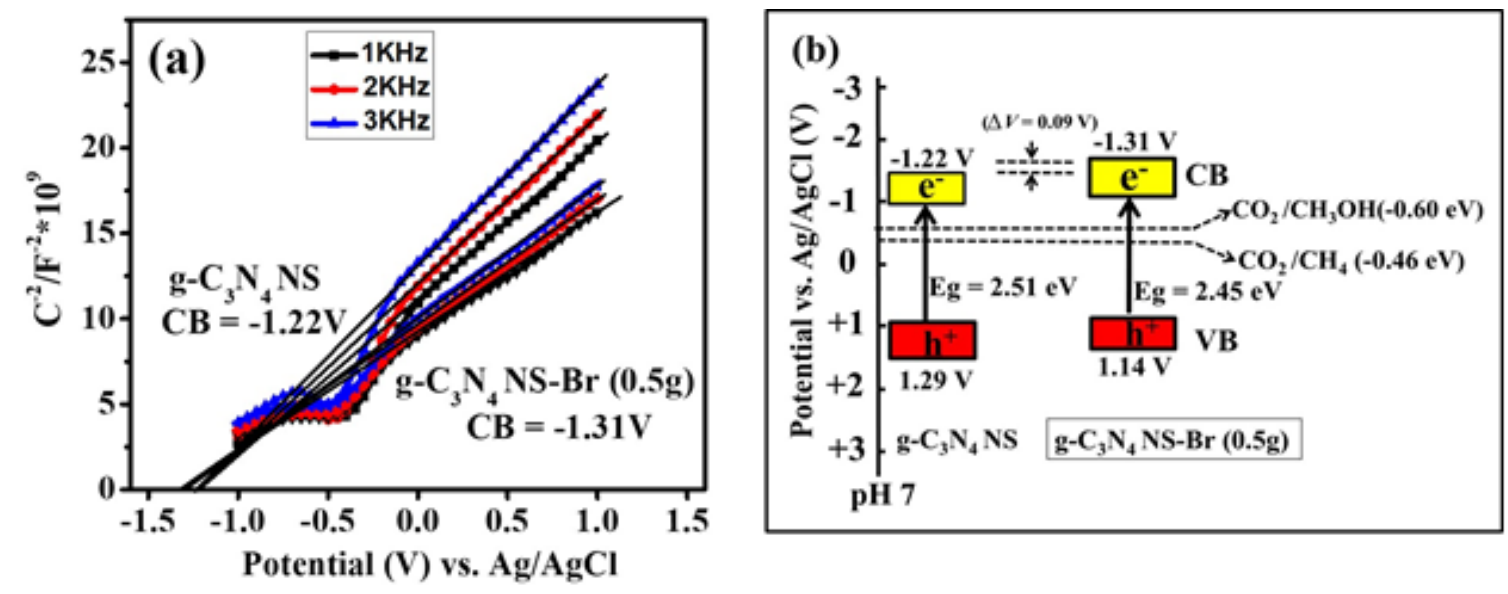

Figure 14. (a) Mott-Schottky plots were carried out at various frequencies. (b) Schematic band energy level alignment for g- $\mathrm{C}_{3} \mathrm{~N}_{4} \mathrm{NS}$ and $\mathrm{Br}$-doped g- $\mathrm{C}_{3} \mathrm{~N}_{4} \mathrm{NS}(0.5 \mathrm{~g})$ samples.

The photocatalytic $\mathrm{CO}_{2}$ reduction activity of the Br-doped $\mathrm{g}-\mathrm{C}_{3} \mathrm{~N}_{4} \mathrm{NS}$ and pure $\mathrm{g}-\mathrm{C}_{3} \mathrm{~N}_{4}$ NS samples into solar fuels was determined under simulated visible light irradiation $(\lambda>400$ $\mathrm{nm})$. The photocatalytic activity analyses were carried out under two distinct controlled conditions. The first experiment was conducted without visible light. The second was in the absence of a photocatalyst that did not produce any solar fuel or hydrocarbon products. This suggests that light irradiation and photocatalyst were two important pre-requites for a photocatalytic reduction of $\mathrm{CO}_{2}$ into solar fuels. This further shows that solar fuels can be generated through a photocatalytic reduction of $\mathrm{CO}_{2}$ with water vapor over a photocatalyst under visible light irradiation. $\mathrm{CH}_{4}$ and $\mathrm{CH}_{3} \mathrm{OH}$ were the major solar fuels or hydrocarbon products generated in the photocatalytic reduction of $\mathrm{CO}_{2}$ process. It can be observed from Figure 15 that $\mathrm{g}_{-} \mathrm{C}_{3} \mathrm{~N}_{4} \mathrm{NS}-\mathrm{Br}(0.5 \mathrm{~g})$ sample yielded high photocatalytic $\mathrm{CO}_{2}$ reduction into solar fuels (i.e., $\mathrm{CH}_{4}$ and $\mathrm{CH}_{3} \mathrm{OH}$ ) compared to other samples, especially pure $\mathrm{g}-\mathrm{C}_{3} \mathrm{~N}_{4} \mathrm{NS}$. The improved photocatalytic activity of $\mathrm{g}-\mathrm{C}_{3} \mathrm{~N}_{4} \mathrm{NS}-\mathrm{Br}(0.5 \mathrm{~g})$ could be attributed to the synergistic effect of the nanosheets constructed and the quantity of the bromine dopant. The unique porous nanosheets architecture constructed has many pores as well as a large surface area. The enhanced porosity increases the transportation of reactive species for photocatalytic activity. Besides, the sample with $0.5 \mathrm{~g} \mathrm{Br}$ dopant has enhanced light-harvesting ability and improved photocatalytic activity. 
To support the enhanced photocatalytic activity observed in the $g-\mathrm{C}_{3} \mathrm{~N}_{4} \mathrm{NS}-\mathrm{Br}(0.5 \mathrm{~g})$ sample, a photoelectrochemical (PEC) analysis was conducted. This analysis was carried out to investigate the charge mobility processes of the photoinduced electrons in the samples prepared and cast on FTO glass. Figure 16 shows the photocurrent-time $(I-t)$ correlation curves of all the samples prepared to exhibit fast photocurrent feedback in their electrodes. It can be observed from Fig 16 that fast and reversible photocurrent responses were obtained for each on-off-cycle for all samples prepared on the electrodes. This indicates that most photogenerated electrons are transported back to unity across the samples to generate photocurrent under visible light irradiation. The $\mathrm{g}-\mathrm{C}_{3} \mathrm{~N}_{4} \mathrm{NS}-\mathrm{Br}(0.5 \mathrm{~g})$ sample produced a significantly higher photocurrent in its electrode relative to the electrodes of other samples. These results indicated low re-sequencing of electrons and holes pairs, effective charge separation, and transfer efficiency (which is consistent with the EIS and PL experiments), resulting in enhanced photocatalytic reduction of $\mathrm{CO}_{2}$ into $\mathrm{CH}_{4}$ and $\mathrm{CH}_{3} \mathrm{OH}$.

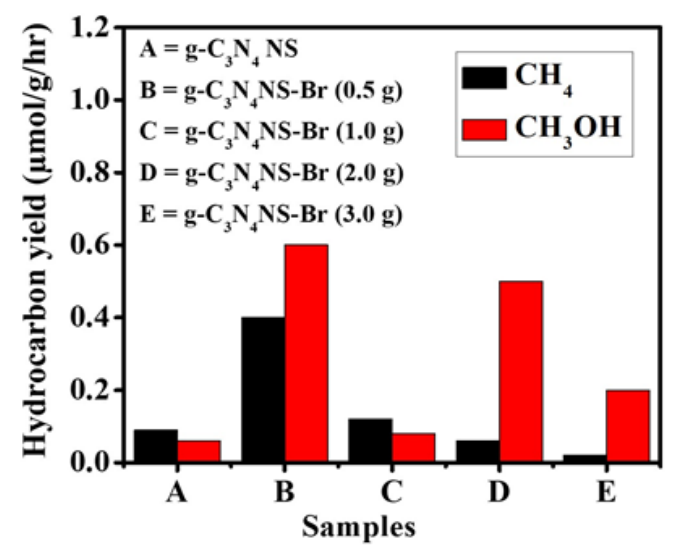

Figure 15. Generation of hydrocarbon products over pure g- $\mathrm{C}_{3} \mathrm{~N}_{4} \mathrm{NS}$ and Br-doped $g-\mathrm{C}_{3} \mathrm{~N}_{4} \mathrm{NS}$ samples under visible light $(\lambda>400 \mathrm{~nm})$ irradiation for $1 \mathrm{~h}$.

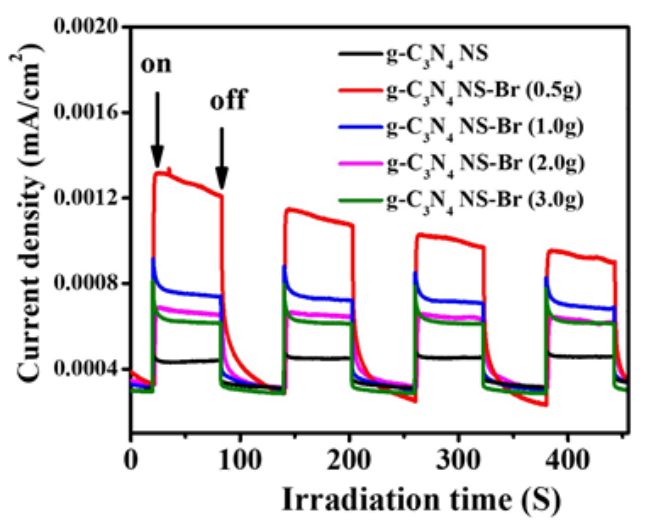

Figure 16. Transient photocurrent responses of pure g- $\mathrm{C}_{3} \mathrm{~N}_{4} \mathrm{NS}$ and $\mathrm{Br}$-doped $\mathrm{g}-\mathrm{C}_{3} \mathrm{~N}_{4} \mathrm{NS}$ samples in $0.5 \mathrm{M} \mathrm{Na}_{2} \mathrm{SO}_{4}$ aqueous solution under visible light irradiation.

\subsection{Electronic structure.}

3.4.1. Structural properties of the doped model.

Figure 17 is the schematic illustration of the unit cell of bromine-doped carbon nitride nanosheet ( $\left.\mathrm{g}-\mathrm{C}_{3} \mathrm{~N}_{4} \mathrm{NS}-\mathrm{Br}\right)$. The optimized lattice parameters computed for the unit cell are $\mathrm{a}=$ $6.987 \AA, b=4.797 \AA$ and $c=6.891 \AA$. The unit cell volume is calculated to be $155.817 \AA 3$. 


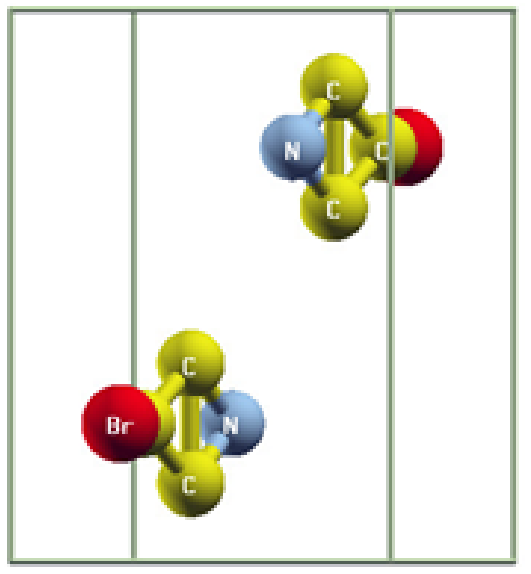

Figure 17. Unit Cell of Br-doped $\mathrm{C}_{3} \mathrm{~N}_{4}$ nanosheet.

The electronic band structure at high-symmetry k-points for the model molecule is shown in Figure 18(a). The band structure of the modeled system shows it is both a wide and direct band-gap material. This makes it a good candidate for photophysical applications because it is a preferred material for the fabrication of optoelectronic devices.

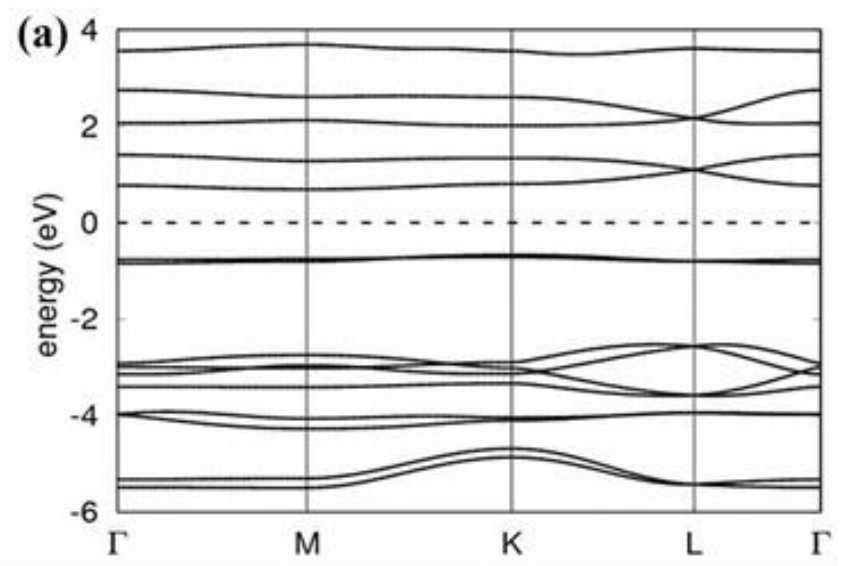

Figure 18. (a) Calculated Band Structure of Br-doped $\mathrm{C}_{3} \mathrm{~N}_{4}$ nanosheet.

The energy band-gap of the optimized structure, Fig. 18(a) has been calculated. The band-gap occurs due to mixed hybridization of $\mathrm{C}$ and $\mathrm{N}$ valence states with that of $\mathrm{Br}$ atoms in the modeled structure. The calculated band gap energy was determined to be $2.05 \mathrm{eV}$, close to the experimental band gap of ca. $2.45 \mathrm{eV}$. It is well noted that DFT/GGA function is known to systematically underpredict band-gap energies [44], which was currently obvious in this study that the calculated band-gap energy was not exact in comparison to the experimental value. However, the difference obtained was not too significant.

Figure 18(c) displays the partial density of electronic states (PDOS) for the molecule under study. For comparison, the Fermi energy level, EF, is set as zero on the energy scales of the energy band-gap, Eg, between occupied and empty atomic orbitals. The same levels are set for the DOS, PDOS, and TDOS. To fully understand the role of each of the contributions from the atomic orbitals to the projected electron density of states (DOS) of the model structure, Figure 18(d) shows in the same plot the DOS and TDOS for the nanosheet. The contributions of individual atoms to the electron density of states (PDOS) are projected out as shown in Figure 18(c). Figure 18(c) reveals that the portions of DOS below $-1 \mathrm{eV}$ are mainly due to contributions from $\mathrm{N}$ and $\mathrm{Br}$ atoms. The central portion, which is above $-1 \mathrm{eV}$, immediately 
around and near the Fermi level is largely due to contributions from the p-orbital states of $\mathrm{N}$ and $\mathrm{C}$ atoms.

In the present work, Figures 18 (b, c, d \& e) show only positive contributions to the total and partial spin-polarized states of electrons for the structure model. Figure 18(c) clearly shows the highest occupied molecular orbitals (HOMO) and the lowest unoccupied molecular orbitals (LUMO) of the model, which lie below and above the Fermi energy level, respectively. From Figure 18(c), it is seen that p-orbitals of $\mathrm{N}$ and $\mathrm{C}$ atoms are the major contributors to the valence band states near to the Fermi level. For the bottom of unoccupied bands, it is seen that the N-p and C-p orbital states are again the major contributors. The top of filled bands and the bottom of unoccupied bands are influenced by the p-orbital states of both nitrogen and carbon atoms.
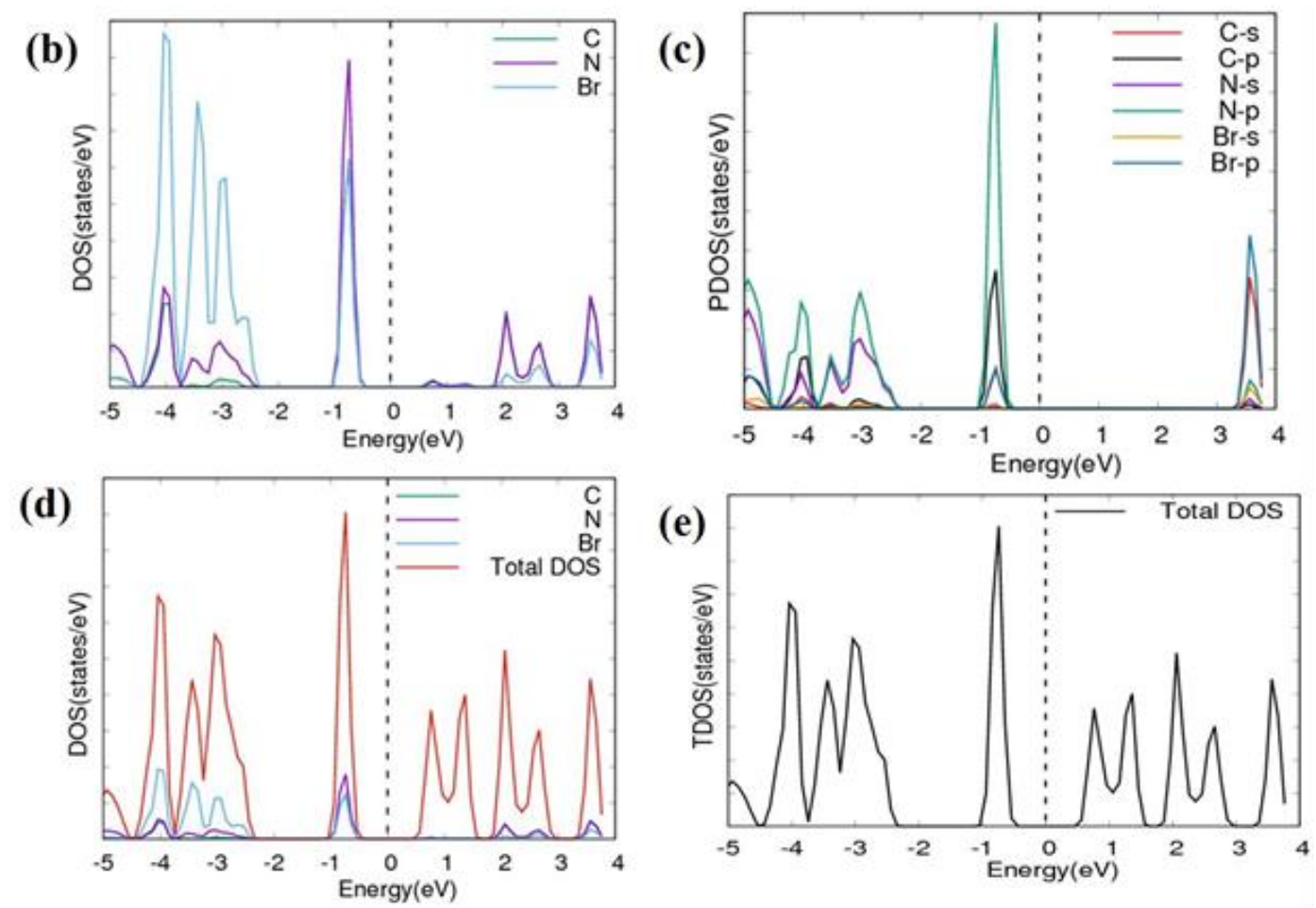

Figure 18. (b) Projected electronic density of states (DOS), (c) Partial density of electronic states (PDOS), (d) Projected electronic density of states (DOS) \& total DOS (TDOS) superimposed, and (e) total DOS (TDOS) for the model system. The Fermi energy level, $\mathrm{E}_{\mathrm{F}}$, is set as zero on the energy scales in all cases.

\section{Conclusions}

Br-doped g- $\mathrm{C}_{3} \mathrm{~N}_{4}$ nanosheets were developed by mixing dicyandiamide with ammonium bromide $\left(\mathrm{NH}_{4} \mathrm{Br}\right)$ in water, dried, and calcinated. The resultant mixture was exfoliated in methanol by ultrasonication leading to ultra-thin nanosheets. The unique $\mathrm{g}-\mathrm{C}_{3} \mathrm{~N}_{4}$ NS-Br $(0.5 \mathrm{~g})$ has enhanced photocatalytic $\mathrm{CO}_{2}$ reduction rate into solar fuels (i.e., $\mathrm{CH}_{4}$ and $\left.\mathrm{CH}_{3} \mathrm{OH}\right)$ compare to other samples. The higher photocatalytic activity exhibited by $\mathrm{g}-\mathrm{C}_{3} \mathrm{~N}_{4}$ NS-Br $(0.5 \mathrm{~g})$ could be attributed to the high porosity, large surface area, excellent lightharvesting capability, and efficient charge separation and mobility of charge carriers. The g$\mathrm{C}_{3} \mathrm{~N}_{4} \mathrm{NS}-\mathrm{Br}(0.5 \mathrm{~g})$ sample possesses excellent band energy level alignment and electronic structure with a calculated band gap energy from DFT to be $2.05 \mathrm{eV}$, which is close to the experimental band gap of ca. $2.45 \mathrm{eV}$. This study shows that morphology tuning of $\mathrm{g}_{-} \mathrm{C}_{3} \mathrm{~N}_{4}$ and doping has a synergistic effect in enhancing photocatalytic activity. Therefore, these are excellent strategies to produce photocatalysts with potential photocatalysis applications, 
optoelectronics, biomechanics, nanoelectronics, nanoelectromechanical systems (NEMS), spintronics, optoelectronics, and photonic devices manufacturing.

\section{Funding}

This research received no external funding.

\section{Acknowledgments}

The authors would like to acknowledge the financial support from the Ghana Government Book and Research Allowance for tertiary institutions. We also acknowledge contributions from members of the Mechanical Engineering Department of the Ho Technical University, Ghana, and the State Key Laboratory of Advanced Technology for Material Synthesis and Processing, Wuhan University of Technology, Wuhan 430070, P.R. China, for supporting the research in diverse ways. Besides, the authors are grateful to the Centre for High-Performance Computing (CHPC), Cape Town, South Africa, for computer time on the Lengau cluster.

\section{Conflicts of Interest}

The authors declare no conflict of interest.

\section{References}

1. Ye, S.; Wang, R.; Wu, M.-Z.; Yuan, Y.-P. A review on g- $\mathrm{C}_{3} \mathrm{~N}_{4}$ for photocatalytic water splitting and $\mathrm{CO}_{2}$ reduction. Appl Surf Sci. 2015, 358, 15-27, https://doi.org/10.1016/j.apsusc.2015.08.173.

2. Ong, W.-J.; Tan, L.-L.; Ng, Y.H.; Yong, S.-T.; Chai, S.-P. Graphitic carbon nitride $\left(\mathrm{g}_{-} \mathrm{C}_{3} \mathrm{~N}_{4}\right)$-based photocatalysts for artificial photosynthesis and environmental remediation: are we a step closer to achieving sustainability?. Chem Rev. 2016, 116, 7159-7329, https://doi.org/10.1021/acs.chemrev.6b00075.

3. Jiang, J.; Cao, S.; Hu, C.; Chen, C. A comparison study of alkali metal-doped g- $\mathrm{C}_{3} \mathrm{~N}_{4}$ for visible-light photocatalytic hydrogen evolution. Chinese J. Catal. 2017, 38, 1981-1989, https://doi.org/10.1016/s18722067(17)62936-x.

4. Liang, L.; Li, K.; Lv, K.; Ho, W.; Duan, Y. Highly photoreactive $\mathrm{TiO}_{2}$ hollow microspheres with super thermal stability for acetone oxidation. Chinese J. Catal. 2017, 38, 2085-2093, https://doi.org/10.1016/s1872-2067(17)62952-8.

5. Cao, S.; Yu, J. Carbon-based $\mathrm{H}_{2}$-production photocatalytic materials. J Photochem Photobiol, C. 2016, 27, 72-99, https://doi.org/10.1016/j.jphotochemrev.2016.04.002.

6. Low, J.; Cheng, B.; Yu, J. Surface modification and enhanced photocatalytic $\mathrm{CO}_{2}$ reduction performance of $\mathrm{TiO}_{2}$ : a review. Appl Surf Sci. 2017, 392, 658-686, https://doi.org/10.1016/j.apsusc.2016.09.093.

7. Lin, J.; Tian, W.; Zhang, H.; Duan, X.; Sun, H.; Wang, S. Graphitic Carbon Nitride-Based Z-Scheme Structure for Photocatalytic $\mathrm{CO}_{2}$ Reduction. Energy \& Fuels. 2020, https://doi.org/10.1021/acs.energyfuels.0c03048.

8. Zhang, G.; Li, G.; Heil, T.; Zafeiratos, S.; Lai, F.; Savateev, A.; Antonietti, M.; Wang, X. Tailoring the grain boundary chemistry of polymeric carbon nitride for enhanced solar hydrogen production and $\mathrm{CO}_{2}$ reduction. Angewandte Chemie International Edition 2019, 58, 3433-3437, https://doi.org/10.1002/anie.201811938.

9. Cao, S.; Low, J.; Yu, J.; Jaroniec, M. Polymeric photocatalysts based on graphitic carbon nitride. Adv Mater. 2015, 27, 2150-2176, https://doi.org/10.1002/adma.201500033.

10. Zhao, Y.; Xu, S.; Sun, X.; Xu, X.; Gao, B. Unique bar-like sulfur-doped $\mathrm{C}_{3} \mathrm{~N}_{4} / \mathrm{TiO}_{2}$ nanocomposite: Excellent visible light driven photocatalytic activity and mechanism study. Appl Surf Sci. 2018, 436,873881, https://doi.org/10.1016/j.apsusc.2017.12.061.

11. Yin, S.; Han, J.; Zhou, T.; Xu, R. Recent progress in g- $\mathrm{C}_{3} \mathrm{~N}_{4}$ based low cost photocatalytic system: activity enhancement and emerging applications. Catal Sci Technol. 2015, 5, 5048-5061, https://doi.org/10.1039/c5cy00938c.

12. Li, Z.; Wang, J.; Zhu, K.; Ma, F.; Meng, A. Ag/g- $\mathrm{C}_{3} \mathrm{~N}_{4}$ composite nanosheets: Synthesis and enhanced visible photocatalytic activities. Mater Lett. 2015, 145, 167-170, https://doi.org/10.1016/j.matlet.2015.01.058.

13. Huang, Q.; Yu, J.; Cao, S.; Cui, C.; Cheng, B. Efficient photocatalytic reduction of $\mathrm{CO}_{2}$ by aminefunctionalized g- $\mathrm{C}_{3} \mathrm{~N}_{4}$. Appl Surf Sci. 2015, 358, 350-355, https://doi.org/10.1016/j.apsusc.2015.07.082. 
14. Akple, M.S.; Low, J.; Wageh, S.; Al-Ghamdi, A.A.; Yu, J.; Zhang, J. Enhanced visible light photocatalytic $\mathrm{H}$ 2-production of g- $\mathrm{C}_{3} \mathrm{~N}_{4} / \mathrm{WS}_{2}$ composite heterostructures. Appl Surf Sci. 2015, 358, 196-203, https://doi.org/10.1016/j.apsusc.2015.08.250.

15. Li, H.-J.; Sun, B.-W.; Sui, L.; Qian, D.-J.; Chen, M. Preparation of water-dispersible porous g-C $3 \mathrm{~N}_{4}$ with improved photocatalytic activity by chemical oxidation. PCCP 2015, 17, 3309-3315, https://doi.org/10.1039/c4cp05020g.

16. Zhu, B.; Zhang, J.; Jiang, C.; Cheng, B.; Yu, J. First principle investigation of halogen-doped monolayer g$\mathrm{C}_{3} \mathrm{~N}_{4}$ photocatalyst. Appl Catal. B 2017, 207, 27-34, https://doi.org/10.1016/j.apcatb.2017.02.020.

17. $\mathrm{Xu}, \mathrm{J}$.; Wang, Y.; Zhu, Y. Nanoporous graphitic carbon nitride with enhanced photocatalytic performance. Langmuir 2013, 29, 10566-10572, https://doi.org/10.1021/la402268u.

18. Niu, P.; Zhang, L.; Liu, G.; Cheng, H.M. Graphene-Like Carbon Nitride Nanosheets for Improved Photocatalytic Activities. Adv Funct Mater. 2012, 22, 4763-4770, https://doi.org/10.1002/adfm.201200922.

19. Sun, J.; Zhang, J.; Zhang, M.; Antonietti, M.; Fu, X.; Wang, X. Bioinspired hollow semiconductor nanospheres as photosynthetic nanoparticles. Nat. Commun. 3 2012, 1139, https://doi.org/10.1038/ncomms2152.

20. Akhundi, A.; Habibi-Yangjeh, A.; Abitorabi, M.; Pouran, R.S. Review on photocatalytic conversion of carbon dioxide to value-added compounds and renewable fuels by graphitic carbon nitride-based photocatalysts. Catal. Rev. 2019, 61, 595-628, https://doi.org/10.1080/01614940.2019.1654224.

21. Fu, J.; Liu, K.; Jiang, K.; Li, H.; An, P.; Li, W.; Zhang, N.; Li, H.; Xu, X.; Zhou, H. Graphitic carbon nitride with dopant induced charge localization for enhanced photoreduction of $\mathrm{CO}_{2}$ to $\mathrm{CH}_{4}$. Adv. Sci. 2019, 6, https://doi.org/10.1002/advs.201900796.

22. Wang, K.; Li, Q.; Liu, B.; Cheng, B.; Ho, W.; Yu, J. Sulfur-doped g- $\mathrm{C}_{3} \mathrm{~N}_{4}$ with enhanced photocatalytic $\mathrm{CO}_{2}$-reduction performance. Appl. Catal. B: 2015, 176, 44-52, https://doi.org/10.1016/j.apcatb.2015.03.045.

23. Jiang, L.; Yuan, X.; Pan, Y.; Liang, J.; Zeng, G.; Wu, Z.; Wang, H. Doping of graphitic carbon nitride for photocatalysis: a reveiw. Appl. Catal. B. 2017, 217, 388-406, https://doi.org/10.1016/j.apcatb.2017.06.003.

24. Kumar, S.; Gawande, M.B.; Kopp, J.; Kment, S.; Varma, R.S.; Zbořil, R. P-and F-co-doped Carbon Nitride Nanocatalysts for Photocatalytic $\mathrm{CO}_{2}$ Reduction and Thermocatalytic Furanics Synthesis from Sugars. ChemSusChem. 2020, 13, 5231-5238, https://doi.org/10.1002/cssc.202001172.

25. Mahvelati-Shamsabadi, T.; Lee, B.-K. Photocatalytic $\mathrm{H}_{2}$ evolution and $\mathrm{CO}_{2}$ reduction over phosphorusdoped g- $\mathrm{C}_{3} \mathrm{~N}_{4}$ nanostructures: Electronic, Optical, and Surface properties. Renew. Sust. Energ. Rev. 2020, 130, https://doi.org/10.1016/j.rser.2020.109957.

26. Xing, F.; Liu, Q.; Song, M.; Huang, C. Fluorine modified boron carbon nitride semiconductors for improved photocatalytic $\mathrm{CO}_{2}$ reduction under visible light. ChemCatChem. 2018, 10, 5270-5279, https://doi.org/10.1002/cctc.201801418.

27. Wang, J.; Cao, S.; Yu, J. Nanocages of Polymeric Carbon Nitride from Low-Temperature Supramolecular Preorganization for Photocatalytic $\mathrm{CO}_{2}$ Reduction. Solar RRL 2019, https://doi.org/10.1002/solr.201900469.

28. Akple, M.S.; Ishigaki, T.; Madhusudan, P. Bio-inspired honeycomb-like graphitic carbon nitride for enhanced visible light photocatalytic $\mathrm{CO}_{2}$ reduction activity. Env. Sci \& Pollut Res 2020, 27, 22604-22618, https://doi.org/10.1007/s11356-020-08804-2.

29. Shen, M.; Zhang, L.; Shi, J. Converting $\mathrm{CO}_{2}$ into fuels by graphitic carbon nitride-based photocatalysts. Nanotechnology 2018, 29, https://doi.org/10.1088/1361-6528/aad4c8.

30. Liu, Q.; Shen, J.; Yu, X.; Yang, X.; Liu, W.; Yang, J.; Tang, H.; Xu, H.; Li, H.; Li, Y. Unveiling the origin of boosted photocatalytic hydrogen evolution in simultaneously $(\mathrm{S}, \mathrm{P}, \mathrm{O})$-Codoped and exfoliated ultrathin g- $\mathrm{C}_{3} \mathrm{~N}_{4}$ nanosheets. Appl. Catal. B. 2019, 248, 84-94, https://doi.org/10.1016/j.apcatb.2019.02.020.

31. Zhou, Y.; Lv, W.; Zhu, B.; Tong, F.; Pan, J.; Bai, J.; Zhou, Q.; Qin, H. Template-free one-step synthesis of g- $\mathrm{C}_{3} \mathrm{~N}_{4}$ nanosheets with simultaneous porous network and S-doping for remarkable visible-light-driven hydrogen evolution. ACS Sustain. Chem. Eng. 2019, 7, 5801-5807, https://doi.org/10.1021/acssuschemeng.8b05374.

32. Sing, K.; Everett, D. W.; Haul, R.A.; Moscou, L.; Pierotti, R.A. Reporting physisorption data for gas/solid systems with special reference to the determination of surface area and porosity. Pure Appl Chem 1985, 57, 603-619, https://doi.org/10.1351/pac198557040603.

33. Giannozzi, P.; Andreussi, O.; Brumme, T.; Bunau, O.; Nardelli, M.B.; Calandra, M.; Car, R.; Cavazzoni, C.; Ceresoli, D.; Cococcioni, M. Advanced capabilities for materials modelling with Quantum ESPRESSO. Journal of Physics: Cond Mat. 2017, 29, https://doi.org/10.1088/1361-648x/aa8f79.

34. Rappe, A.M.; Rabe, K.M.; Kaxiras, E.; Joannopoulos, J. Optimized pseudopotentials. Phys. Rev. B Condens. Matter. 1990, 41, 1227-1230, https://doi.org/10.1103/physrevb.41.1227.

35. Perdew, J.P.; Burke, K.; Ernzerhof, M. Generalized gradient approximation made simple. Physical review letters 1996, 77, 3865-3868, https://doi.org/10.1103/physrevlett.77.3865.

36. Björkman, T.; Grånäs, O. Adaptive smearing for Brillouin zone integration. Int. J. Quantum Chem. 2011, 111, 1025-1030, https://doi.org/10.1002/qua.22476.

37. Fletcher, R. Practical methods of optimization. John wiley \& sons. New York 1987, 80.

38. Monkhorst, H.J.; Pack, J.D. Special points for Brillouin-zone integrations. Physical Review B: Condensed Matter 1976, 13, 5188-5192, https://doi.org/10.1103/physrevb.13.5188. 
39. Song, X.; Li, X.; Zhang, X.; Wu, Y.; Ma, C.; Huo, P.; Yan, Y. Fabricating C and O co-doped carbon nitride with intramolecular donor-acceptor systems for efficient photoreduction of $\mathrm{CO}_{2}$ to CO. Appl Catal. B 2020, 268, https://doi.org/10.1016/j.apcatb.2020.118736.

40. Jiang, L.; Yuan, X.; Zeng, G.; Liang, J.; Wu, Z.; Yu, H.; Mo, D.; Wang, H.; Xiao, Z.; Zhou, C. Nitrogen self-doped $\mathrm{g}-\mathrm{C}_{3} \mathrm{~N}_{4}$ nanosheets with tunable band structures for enhanced photocatalytic tetracycline degradation. J Colloid Interface Sci 2019, 536, 17-29, https://doi.org/10.1016/j.jcis.2018.10.033.

41. Cao, S.; Fan, B.; Feng, Y.; Chen, H.; Jiang, F.; Wang, X. Sulfur-doped g- $\mathrm{C}_{3} \mathrm{~N}_{4}$ nanosheets with carbon vacancies: general synthesis and improved activity for simulated solar-light photocatalytic nitrogen fixation. Chem. Eng. J. 2018, 353, 147-156, https://doi.org/10.1016/j.cej.2018.07.116.

42. Bulusheva, L.G.; Okotrub, A.V.; Flahaut, E.; Asanov, I.P.; Gevko, P.N.; Koroteev, V.; Fedoseeva, Y.V.; Yaya, A.; Ewels, C.P. Bromination of double-walled carbon nanotubes. Chem. Mater 2012, 24, 2708-2715, https://doi.org/10.1021/cm3006309.

43. Smykalla, L.; Shukrynau, P.; Korb, M.; Lang, H.; Hietschold, M. Surface-confined 2D polymerization of a brominated copper-tetraphenylporphyrin on $\mathrm{Au}$ (111). Nanoscale 2015, 7, 4234-4241, https://doi.org/10.1039/c4nr06371f.

44. Akple, M.S.; Apevienyeku, H.K. Synthesis and density-functional-theory calculations of electronic band structure of hollow sphere $\mathrm{WS}_{2}$. Materials Science-Poland 2018, 36, 409-418, https://doi.org/10.2478/msp2018-0052. 